Journal of Pediatric Gastroenterology and Nutrition, Publish Ahead of Print DOI : 10.1097/MPG.0000000000002424

\title{
Diagnostic delays in children with coeliac disease in the Central European region
}

Petra Riznik $^{\mathrm{a}}$, MD, Luigina De Leo ${ }^{\mathrm{b}}, \mathrm{PhD}$, Jasmina Dolinsek $^{\mathrm{c}}$, MSc, Judit Gyimesi ${ }^{\mathrm{d}}$, MD, Martina Klemenak $^{\mathrm{a}}$, MD, PhD, Berthold Koletzko ${ }^{\mathrm{e}, \mathrm{f}}, \mathrm{MD}, \mathrm{PhD}$, Sibylle Koletzko ${ }^{\mathrm{g}, \mathrm{m}}, \mathrm{MD}$, PhD, Ilma Rita Korponay-Szabó ${ }^{\mathrm{d}, \mathrm{h}}, \mathrm{MD}, \mathrm{PhD}$, Tomaz Krencnik $^{\mathrm{a}}$, MD, Tarcisio Not ${ }^{\mathrm{b}}$, MD, PhD, Goran Palcevski ${ }^{i}$, MD, PhD, Daniele Sblattero ${ }^{\mathrm{j}}$, PhD, Matej Vogrincic ${ }^{\mathrm{k}}$, Katharina Julia Werkstetter $^{\mathrm{g}}$, MSc, MPH, Jernej Dolinsek ${ }^{\mathrm{a}, 1}, \mathrm{MD}, \mathrm{PhD}$

${ }^{a}$ University Medical Centre Maribor, Department of Paediatrics, Gastroenterology, Hepatology and Nutrition Unit, Maribor, Slovenia; ${ }^{b}$ IRCCS Burlo Garofolo Trieste, Institute for Maternal and Child Health, Trieste, Italy; ${ }^{c}$ Municipality of Maribor, Project Office, Maribor, Slovenia; ${ }^{\mathrm{d}}$ Heim Pál National Paediatric Institute, Coeliac Disease Centre, Budapest, Hungary; 'Stiftung Kindergesundheit (Child Health Foundation), Munich, Germany; ${ }^{\mathrm{f} D i v i s i o n}$ of Metabolic Diseases and Nutritional Medicine, Department of Pediatrics, Dr. von Hauner Children's Hospital, University Hospital, LMU Munich, Munich, Germany; ${ }^{\mathrm{g}}$ Department of Pediatrics, Dr. von Hauner Children's Hospital, University Hospital, LMU Munich, Munich, Germany; ${ }^{\mathrm{m}}$ Department of Pediatrics, Gastroenterology and Nutrition, School of

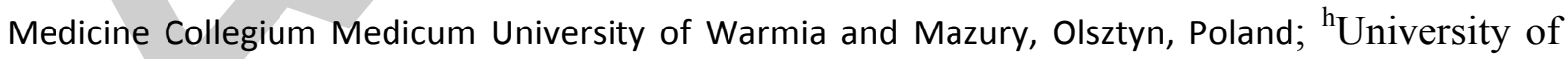
Debrecen, Faculty of Medicine, Department of Paediatrics, Debrecen, Hungary; ${ }^{\mathrm{i}}$ University Hospital Rijeka, Department for Gastroenterology, Paediatric clinic, Rijeka, Croatia; ${ }^{\mathrm{j}}$ University of Trieste, Trieste, Italy; ${ }^{\mathrm{k}}$ University Medical Centre Maribor, Department of 
Informatics, Maribor, Slovenia; ${ }^{1}$ Medical Faculty, Department of Paediatrics, University of Maribor, Maribor, Slovenia

Corresponding author: Jernej Dolinsek, MD, $\mathrm{PhD}$, University Medical Centre Maribor, Department of Paediatrics, Gastroenterology, Hepatology and Nutrition Unit. Ljubljanska 5, 2000 Maribor, Slovenia. Phone: 0038623212110, email: jernej.dolinsek@ukc-mb.si

\section{Conflicts of Interest and Source of Funding:}

Authors have no conflicts of interest to disclose.

The study was supported by the Interreg Central Europe CE-111 Focus in CD project. The collection of Hungarian data was also supported by the NKFI120392 and EFOP-3.6.1-162016-00022 grants, the collection of German data by Medical Faculty, Ludwig Maximilian University Munich and Bavarian State Ministry for Education, Culture, Science and Arts, and the collection of Slovenian data by Slovenian Research Agency (ARRS). 


\section{Abstract}

Objectives

Coeliac disease (CD) is a systemic autoimmune disorder affecting about $1 \%$ of the population. Many patients remain undiagnosed or are diagnosed with substantial delay. We assessed diagnostic delays in symptomatic CD children in Central Europe (CE).

Methods

Paediatric gastroenterologists in five CE countries retrospectively reported data of their patients diagnosed in 2016. Age at first CD related symptom(s), first visit to paediatric gastroenterologist and confirmed diagnosis were used to determine diagnostic delays.

Results

Data from 393 children (65\% female, median age 7 years, range $7 \mathrm{~m}-18.5 \mathrm{y})$ from Croatia, Hungary, Germany, Italy and Slovenia were analysed. Median duration from first symptom(s) to visit to paediatric gastroenterologist was 5 months (range $0-10 \mathrm{y}$; preschool $4 \mathrm{~m}$, school-aged $5 \mathrm{~m}$ ), and further duration until final diagnosis was 1 month (range $0-5 \mathrm{y}$ ) with significant regional differences $(\mathrm{p}<0.001)$. Median diagnostic delay was 6 months (range 0-10y; preschool 5m, school-aged $7 \mathrm{~m}$ ). Type of clinical presentation had little, however significant effect on delays. Reduced body mass in delays longer than 3 years compared to delays shorter than 1 year was found ( $\mathrm{z}$-score -0.93 vs $-0.39, \mathrm{p}<0.05)$.

\section{Conclusions}

Time from first symptoms to CD diagnosis in children in five CE countries is slightly shorter compared to few other small paediatric studies, and significantly shorter than reported for adults. Nevertheless, delays of more than 3 years in $6.6 \%$ of children are worrisome. Raising awareness about the variable symptoms and implementation of reliable diagnostic tools will further reduce diagnostic delays.

Key words: coeliac disease, children, diagnostic delays, Central Europe 


\section{What Is Known}

- Diagnostic delays in coeliac disease can be very long and data between regions vary substantially.

- Studies showed that in adults the delays are longer than in children, with a low number of children included in these studies.

\section{What Is New}

- Diagnostic delays in children with coeliac disease in Central Europe are short based on this multicentre study using reliable medical records.

- Different clinical presentations do not yield important differences in delays.

- Long delays lead to lower body mass in children. 


\section{INTRODUCTION}

Coeliac disease (CD) is a lifelong systemic autoimmune disorder, elicited by gluten and related prolamines in genetically susceptible individuals (1). It is one of the most common chronic illnesses and affects about $1 \%$ of the population (2-5). Due to its genetic predisposition, $\mathrm{CD}$ is more common among family members of affected individuals, and is associated with a number of other conditions $(1,6-8)$. CD may be asymptomatic and should be screened for in persons belonging to the increased risk groups. Clinical presentation of the disease is very diverse; the Oslo classification defines several types of CD - classical, symptomatic but non-classical, subclinical, asymptomatic, refractory and potential CD (9). During the past decades, due to the better serological screening tests more CD cases without the classical presentation are diagnosed, thus changing the clinical presentation of the disease at diagnosis from the historically classic symptoms of malabsorption to now more nonclassical oligosymptomatic or even asymptomatic presentations (4,10-12).

The European Society for Paediatric Gastroenterology, Hepatology and Nutrition (ESPGHAN) published recommendations for the diagnosis of CD that include determination of $\mathrm{CD}$ specific autoantibodies against tissue transglutaminase (TGA) followed by upper endoscopy with multiple duodenal biopsies, which can be omitted in selected cases with very high titres of TGA and positive confirmatory tests (1,13-15).

The only available treatment of CD is a lifelong strict gluten-free diet $(1,6,16)$. The adherence to the diet is important since untreated disease may lead to serious complications $(10,17)$.

Despite being one of the most common lifelong disorders, CD remains undiagnosed for a long time in the majority of adult and paediatric patients. In some regions, diagnostic delays 
reached up to and even more than 10 years, which adversely affects patients' quality of life and health (18-29).

The aim of our study was to identify in symptomatic children in the Central European (CE) region the time interval between first occurrence of symptoms and final diagnosis and to identify potential factors related to prolonged diagnostic delays.

\section{METHODS}

The study was carried out between the end of March and the middle of August 2017, as a part of the Focus IN CD project (CE-111), co-financed by the Interreg CE Programme. Twelve partners from five CE countries (Croatia, Germany, Hungary, Italy and Slovenia) participate in the project.

\section{Participants and study design}

Paediatric gastroenterologists from the included regions were asked by the regional project partners to complete a web-based survey, providing anonymized medical records of children and adolescents below 19 years of age who were diagnosed with CD in 2016. In Croatia, Hungary and Slovenia the majority of $\mathrm{CD}$ patients diagnosed by paediatric gastroenterologists during this year were included, since almost all centres in the country participated in the study.-The inclusion criteria with flowchart are presented in Figure 1. Patients detected as a result of screening for risk conditions (family risk or associated diseases) were excluded if CD-related symptoms were not present. The questionnaire (https://www.interreg-central.eu/Content.Node/surveys.html) was translated into the languages of all project partners and focused on clinical presentation, the diagnostic methods used, and the duration of symptoms prior to diagnosis. We analysed medical records of all 
included $\mathrm{CD}$ patients, focusing on the age at diagnosis and the duration between first $\mathrm{CD}$ related symptoms, first visit to paediatric gastroenterologist and confirmation of the diagnosis. Differences between preschool $(<6 y)$ and school-aged $(\geq 6 y)$ children were studied and regional differences regarding the studied parameters analysed. We investigated also the impact of different clinical presentations of $\mathrm{CD}$ on the diagnostic delays. Patients were divided into two groups according to the Oslo classification (9) - classical CD (diarrhoea and/or malabsorption - fatty stool, weight loss, growth retardation, anaemia) and nonclassical CD (any other symptoms). Skin manifestation of CD - Dermatitis Herpetiformis Duhring (DHD) was regarded as a separate entity. We further divided the group of classical $\mathrm{CD}$ into malabsorption with and without diarrhoea, and non-classical CD into the group with abdominal symptoms (including pain) and group with non-specific non-gastrointestinal symptoms.

\section{Statistical analysis}

Statistical analysis was performed using IBM SPSS Statistics 22.0 for Windows. One-way ANOVA, Mann-Whitney U test and Kruskal-Wallis H test with post hoc test, together with Spearman's rank correlation tests were used for the analysis.

The study was approved by the National Medical Ethics Committee of the Republic of Slovenia (0120-383).

\section{RESULTS}

After exclusion of 128 patients with a lack of data on the time of first symptoms $(n=107)$ or first visit to paediatric gastroenterologist $(n=21)$, data from 393 symptomatic children and adolescents from Croatia $(n=38)$, Germany $(n=27)$, Hungary $(n=237)$, Italy $(n=57)$ and 
Slovenia ( $n=34)$ were available for analysis (Table 1). Median age of the children at the time of diagnosis was 7 years (range $7 \mathrm{~m}-18.5 \mathrm{y}$ ), $65 \%$ were female and more than two thirds of them were diagnosed before the age of 10 years.

Median duration from the first CD related symptoms to the first visit to the paediatric gastroenterologist was 5 months (range 0-10y; preschool 4m, school-aged $5 \mathrm{~m}$ ), without significant differences between countries. Median duration from the first visit to the paediatric gastroenterologist to the confirmation of the diagnosis was 1 month (range $0-5 y$; preschool 1m, school-aged $1 \mathrm{~m}$ ), with significantly shorter time interval in Germany compared to Hungary $(\mathrm{p}<0.05)$ and Croatia $(\mathrm{p}<0.05)$, and in Italy compared to Croatia $(\mathrm{p}<0.05)$. Median delay from the first symptoms to diagnosis was 6 months (range $0-10 y$; preschool $5 \mathrm{~m}$, school-aged $7 \mathrm{~m}$ ) with no significant differences between countries (Table 1 and Figure 2).

Using Spearman's rank correlation test we found a weak positive correlation between the age at the diagnosis and diagnostic delays $\left(\mathrm{r}_{\mathrm{s}}=0.24, \mathrm{p}<0.001\right)$.

In $26.7 \%$ of patients $(n=105)$ diagnostic delay was longer than one year and in $12.0 \%(n=47)$ longer than two years. In $6.6 \%$ of patients $(n=26)$ the delay in diagnosis exceeded three years. Median age at the time of diagnosis of these patients was 9 years and $73.1 \%$ of them were female.

We also compared diagnostic delays in relation to clinical presentation of CD (Table 2). Sixty-one percent of patients $(n=241)$ had more than 2 symptoms at the confirmation of the diagnosis without significant differences regarding the diagnostic delays when comparing them with patients having just one or two symptoms. 
Patients with non-classical presentation of $\mathrm{CD}$ had a longer duration from the first visit to the paediatric gastroenterologist to confirmation of the diagnosis compared to those with classical CD $(\mathrm{p}<0.05)$. Significantly longer duration from the first CD related symptoms to the first visit to the paediatric gastroenterologist was found in the group of patients with signs and symptoms of malabsorption without diarrhoea compared to those with malabsorption with diarrhoea $(\mathrm{p}<0.05)$. However, in this group the diagnosis of $C D$ after the visit was established faster than in the group of patients with abdominal symptoms $(\mathrm{p}<0.05)$.

Among patients with classical CD shorter duration from the first symptoms to the first visit to the paediatric gastroenterologist $(p<0.05)$ and to CD diagnosis $(p<0.05)$ was found in those having diarrhoea (Table 2).

Children with CD had a lower body weight (median z-score for weight for age based on the World Health Organization (WHO) growth standard: -0.44; min -4.59; max 3.53), whereas their height was equal to the median of the WHO standard (median z-score for height: -0.07 ; min -4.60; max 7.29). Patients with diagnostic delays longer than 3 years $(n=26)$ had lower body weight and shorter stature compared to those with delays one year or less (z-score for weight: -0.93 and -0.39 respectively, $\mathrm{p}<0.05$; $\mathrm{z}$-score for height: -0.50 and -0.04 respectively; NS). We observed a weak inverse relation between diagnostic delays and z-scores for weight $\left(\mathrm{r}_{\mathrm{s}}=-0.105, \mathrm{p}<0.05\right)$ and height $\left(\mathrm{r}_{\mathrm{s}}=-0.115, \mathrm{p}<0.05\right)$.

\section{DISCUSSION}

Our data shows relatively short median diagnostic delay of 6 months in children with CD in five Central European countries, which are lower compared to available data from other regions (18-31). Within Central Europe, we found only modest regional differences in delay 
between the onset of symptoms and the final diagnosis, however the interval between the first visit to paediatric gastroenterologist and the final diagnosis varied significantly. Regional differences could be attributed to different availability of diagnostic methods and/or capacity of paediatric gastroenterology service.

To our knowledge, the present study is the first study assessing diagnostic delays in children with $\mathrm{CD}$ in the Central European region and also one of the very few in which documented data were obtained from medical records rather than being based on retrospective recall of patients with CD.

There are only few similar studies in paediatric populations. In 2005, Rashid et al (20) evaluated the clinical features of 168 children with biopsy proven $\mathrm{CD}$ in Canada, using a questionnaire completed by children or their parents. They reported a median delay from the onset of symptoms to CD diagnosis of 1 year (20).

In Spain, Rodrigo-Sáez et al analysed the differences between paediatric and adult CD and found that adults have a longer median diagnostic delay (4 years) than children (1 year) (22). Their study was retrospective, based on available medical data, and the diagnostic delays in 43 included children were somewhat longer than ours. In 2015, Navalon-Ramon et al (27) determined the prevalence and clinical features of CD in Valencia, Spain. They also used a questionnaire, completed by adult $\mathrm{CD}$ patients $(n=65)$ or parents of 41 children with $C D$, and discovered mean diagnostic delay of adult patients of 7.97 years and in the paediatric population of 0.68 years, which is only slightly longer than in our study, however they did not report median value of the delay. They assumed that shorter diagnostic delays in paediatric population are mostly due to a higher awareness about $\mathrm{CD}$ among paediatricians. 
However, they found a very low prevalence of diagnosed CD and concluded that a considerable number of CD patients remained undiagnosed (27).

Diagnostic delays in adult studies were mostly determined by patient questionnaires. All of the studies found significantly longer delays compared to the available paediatric studies, with the duration from the first symptoms to the confirmed diagnosis reaching up to 13 years $(18,19,21,23,24,29-31)$. Authors of these studies assumed that long delays are primarily due to the perception among physicians that CD is a rare disease (19) and that the awareness of $\mathrm{CD}$ needs to be improved (24). One of the reasons probably lies in poor recognition of the disease by primary care physicians due to the diverse clinical presentation of CD (24).

This is supported by data from Sweden in 2011, where authors found a decrease in delays and concluded that this was probably caused by increased awareness of CD and the introduction of serological testing (23). Authors of a similar study in Finland conducted in 2014 concluded that factors associated with decreased delays are also the introduction of national guidelines for $\mathrm{CD}$, training of the primary care physicians in early recognition of $\mathrm{CD}$, and the shift of the site of diagnosis from secondary and tertiary to primary care (25).

When analysing diagnostic delays in relation to clinical presentation in our study, diagnostic delays tended to be slightly shorter in patients with classical symptoms, probably since this clinical presentation is more widely known as characteristic for CD. In addition, in patients with non-classical symptoms the duration from the first visit to the paediatric gastroenterologist to the diagnosis was significantly longer compared to those with classical clinical presentation, indicating a somewhat lower awareness of paediatric gastroenterologists on the diverse clinical presentation of $\mathrm{CD}$. This observation could contribute to relatively 
short delays found in our study. It is somewhat surprising that delays were longer in patients having DHD. However, due to its rare occurrence in childhood, many health care professionals may not immediately diagnose a skin rash as a DHD. In our study, median diagnostic delay in patients with DHD as the only symptom was 8 months, however the number of patients presenting with DHD in our study was too low.

Only few other studies, all performed in adults, compared the delays in relation to clinical presentation. Longer delays found in non-classical $\mathrm{CD}$, again suggest important role of the lack of awareness $(18,21,25,29)$.

One of the limitations of our study is the small number of participating diagnostic centres in some countries, which did not allow us to get the complete insight into the patient management in these regions. The short time between first visit to the paediatric gastroenterologist and final diagnosis in our study was associated with the predominance of large, experienced clinical facilities in those datasets. The number of included patients differs between participating countries, with more patients in Hungary than in other countries. In addition, there is a possibility of a positive selection bias in some regions, meaning that the voluntarily participating physicians who provided the data were those who have greater interest in CD and achieve a definite diagnosis faster than the others. Diagnostic delays in these regions may have been longer if other physicians including primary care paediatricians and adult care physicians would have contributed their patients' medical data. However, we were able to include majority of patients diagnosed with $\mathrm{CD}$ from Croatia, Hungary and Slovenia, which is an important strength of our study. A further limitation is the retrospective nature of assessment of existing health care records, with important number of patients where exact onset of symptoms was not recorded, possibly influencing calculated delays. 
To conclude, diagnostic delays in symptomatic children diagnosed with $\mathrm{CD}$ in five Central European countries are rather short, which is in line with other paediatric studies, and significantly shorter than reported in adult studies. This may in some way be attributed to the different and relatively homogenous healthcare systems in included regions compared to countries where previous similar studies were made. In addition, strong coeliac disease societies with long tradition and good cooperation with health care practitioners in included regions may have a role in shorter diagnostic delays, playing an important part in raising awareness about the disease. It remains unclear however in how many symptomatic children the diagnosis is missed and are only diagnosed during the adulthood or not at all. Longer delays in non-classical $\mathrm{CD}$ suggest such possibility. It is also important to note that an important proportion of children $(6.6 \%)$ remain undiagnosed unacceptably long (more than three years). This increases a risk of severe complications, which can have profound negative effect on quality of life of CD patients. Awareness about the disease prevalence, changes in clinical presentation, and the availability of reliable diagnostic methods must thus be improved in order to further reduce delays and the unnecessary burden of undetected and thus untreated disease.

\section{ACKNOWLEDGEMENTS}

The authors wish to thank all the participating physicians from Croatia, Germany, Hungary, Italy, and Slovenia, who uploaded their patients' medical records, thus enabling us to do the study. We are also grateful to all the project partners, who helped in designing the questionnaire and its translation to the partner languages as well as in distributing the questionnaire to the physicians from participating regions. 
Abbreviations: CD: coeliac disease; CE: Central Europe; ESPGHAN: European Society for Paediatric Gastroenterology, Hepatology and Nutrition; EMA; antiendomysium antibodies; TGA: tissue transglutaminase antibodies; HLA: human leucocyte antigen; PaedGI: Paediatric gastroenterologist; m: month; y: year; DHD: Dermatitis Herpetiformis Duhring; WHO: World Health Organization. 


\section{REFERENCES}

1. Husby S, Koletzko S, Korponay-Szabó IR, et al. European Society for Paediatric Gastroenterology, Hepatology and Nutrition guidelines for the diagnosis of coeliac disease. J Pediatr Gastroenterol Nutr 2012;54:136-60.

2. Catassi C, Gatti S, Fasano A. The new epidemiology of celiac disease. J Pediatr Gastroenterol Nutr 2014;59:S7-9.

3. Altobelli E, Paduano R, Petrocelli R, et al. Burden of celiac disease in Europe: a review of its childhood and adulthood prevalence and incidence as of September 2014. Ann Ig 2014;26:485-98.

4. Lebwohl B, Sanders DS, Green PHR. Coeliac disease. Lancet 2018;391:70-81.

5. Laass MW, Schmitz R, Uhlig HH, et al. The prevalence of celiac disease in children and adolescents in Germany. Dtsch Arztebl Int 2015;112:553-60.

6. Parzanese I, Qehajaj D, Patrinicola F, et al. Celiac disease: From pathophysiology to treatment. World J Gastrointest Pathophysiol 2017;8:27-38.

7. Dubé C, Rostom A, Sy R, et al. The prevalence of celiac disease in average-risk and atrisk Western European populations: a systematic review. Gastroenterology 2005;128:S57-67.

8. Ludvigsson JF, Card TR, Kaukinen K, et al. Screening for celiac disease in the general population and in high-risk groups. United European Gastroenterol J 2015;3:106-20.

9. Ludvigsson JF, Leffler DA, Bai JC, et al. The Oslo definitions for coeliac disease and related terms. Gut 2013;62:43-52.

10. Fasano A. Clinical presentation of celiac disease in the pediatric population. Gastroenterology 2005;128:S68-73.

11. Rampertab SD, Pooran N, Brar P, et al. Trends in the presentation of celiac disease. Am J Med 2006;119:355.e9-14. 
12. Ravikumara M, Tuthill DP, Jenkins HR. The changing clinical presentation of coeliac disease. Arch Dis Child 2006;91:969-71.

13. Kowalski K, Mulak A, Jasinska M, et al. Diagnostic challenges in celiac disease. Adv Clin Exp Med 2017;26:729-37.

14. Reilly NR, Husby S, Sanders DS, et al. Coeliac disease: to biopsy or not? Nat Rev Gastroenterol Hepatol 2018;15:60-6.

15. Werkstetter KJ, Korponay-Szabó IR, Popp A, et al. Accuracy in diagnosis of celiac disease without biopsies in clinical practice. Gastroenterology 2017;153:924-35.

16. Theethira TG, Dennis M. Celiac disease and the gluten-free diet: consequences and recommendations for improvement. Dig Dis 2015;33:175-182.

17. Goddard CJ, Gillett HR. Complications of coeliac disease; are all patients at risk? Postgrad Med J 2006;82:705-12.

18. Davidson AG, Campbell JA. Celiac disease and dermatitis herpetiformis: National survey indicates delays in diagnosis. Can Fam Physician 1992;38:2604-8.

19. Green PHR, Stavropoulos SN, Panagi SG, et al. Characteristics of adult celiac disease in the USA: results of a national survey. Am J Gastroenterol 2001;96:126-31.

20. Rashid M, Cranney A, Zarkadas M, et al. Celiac disease: evaluation of the diagnosis and dietary compliance in Canadian children. Pediatrics 2005;116:e754-e759.

21. Gray AM, Papanicolas IN. Impact of symptoms on quality of life before and after diagnosis of coeliac disease: results from a UK population survey. BMC Health Serv Res $2010 ; 10: 1-7$

22. Rodrigo-Sáez L, Fuentes-Álvarez D, Pérez-Martínez I, et al. Differences between pediatric and adult celiac disease. Rev Esp Enferm Dig 2011;103:238-44.

23. Norström F, Lindholm L, Sandström O, et al. Delay to celiac disease diagnosis and its implications for health-related quality of life. BMC Gastroenterol 2011;11:1-8. 
24. Pulido O, Zarkadas M, Dubois S, et al. Clinical features and symptom recovery on a gluten-free diet in Canadian adults with celiac disease. Can J Gastroenterol 2013;27:44953.

25. Fuchs V, Kurppa K, Huhtala H, et al. Factors associated with long diagnostic delay in celiac disease. Scand J Gastroenterol 2014;49:1304-10.

26. Biagi F, Schiepatti A, Malamut G, et al. PROgnosticating COeliac patieNts SUrvivaL: the PROCONSUL score. PLoS One 2014;9:1-5.

27. Navalón-Ramon E, Juan-García Y, Pinzón-Rivadeneira A. Prevalence and features of coeliac disease in the Mediterranean area of Spain. Semergen 2016;42:514-22.

28. Vavricka SR, Vadasz N, Stotz M, et al. Celiac disease diagnosis still significantly delayed - Doctor's but not patients' delay responsive for the increased total delay in women. Dig Liver Dis 2016;48:1148-54.

29. Paez MA, Gramelspacher AM, Sinacore J, et al. Delay in diagnosis of celiac disease in patients without gastrointestinal complaints. Am J Med 2017;130:1318-23.

30. Dickey W, McConnell JB. How many hospital visits does it take before celiac sprue is diagnosed? J Clin Gastroenterol 1996;23:21-3.

31. Cranney A, Zarkadas M, Graham ID, et al. The Canadian celiac health survey. Dig Dis Sci 2007;52:1087-95. 
Figure 1. Data collection flowchart for children and adolescents diagnosed with CD. PaedGi

- paediatric gastroenterologist.

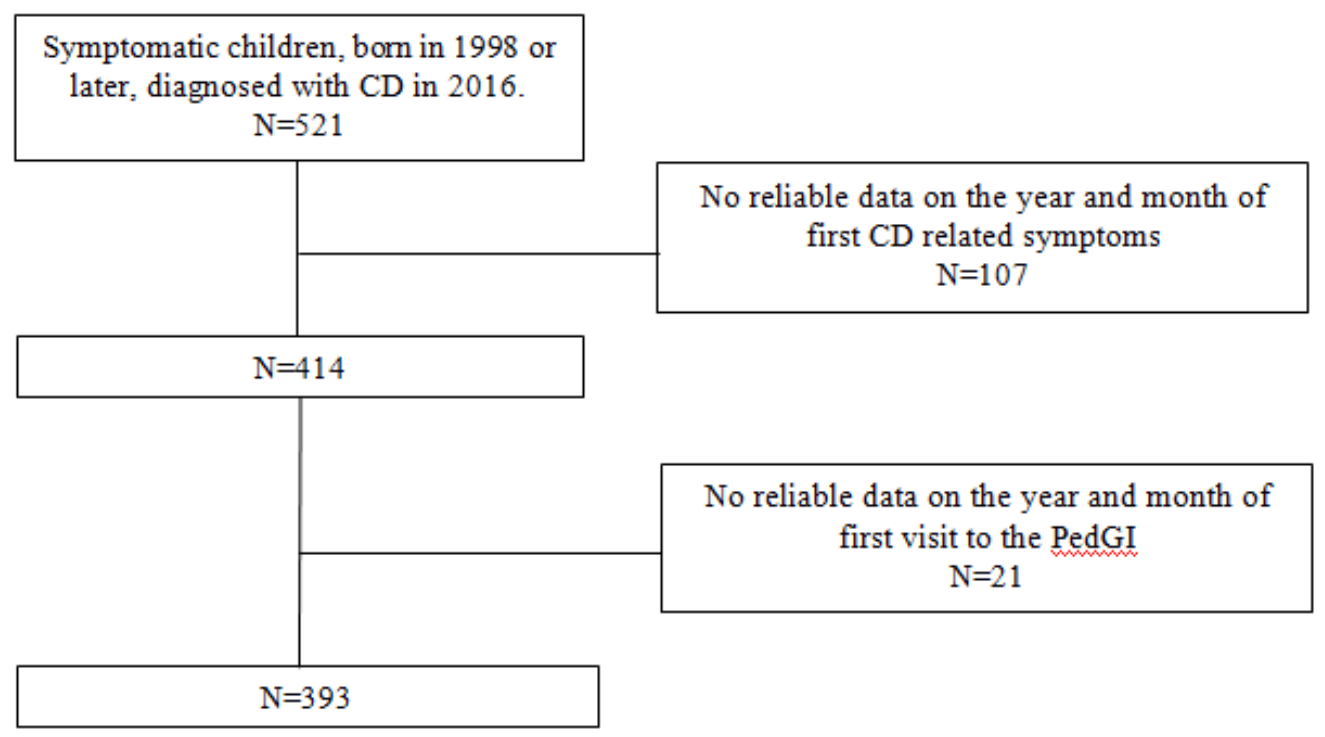


Figure 2. Diagnostic delays in children with CD in Central European region. No statistically significant differences were found between countries. Horizontal line marks the diagnostic delays lasting more than 3 years.

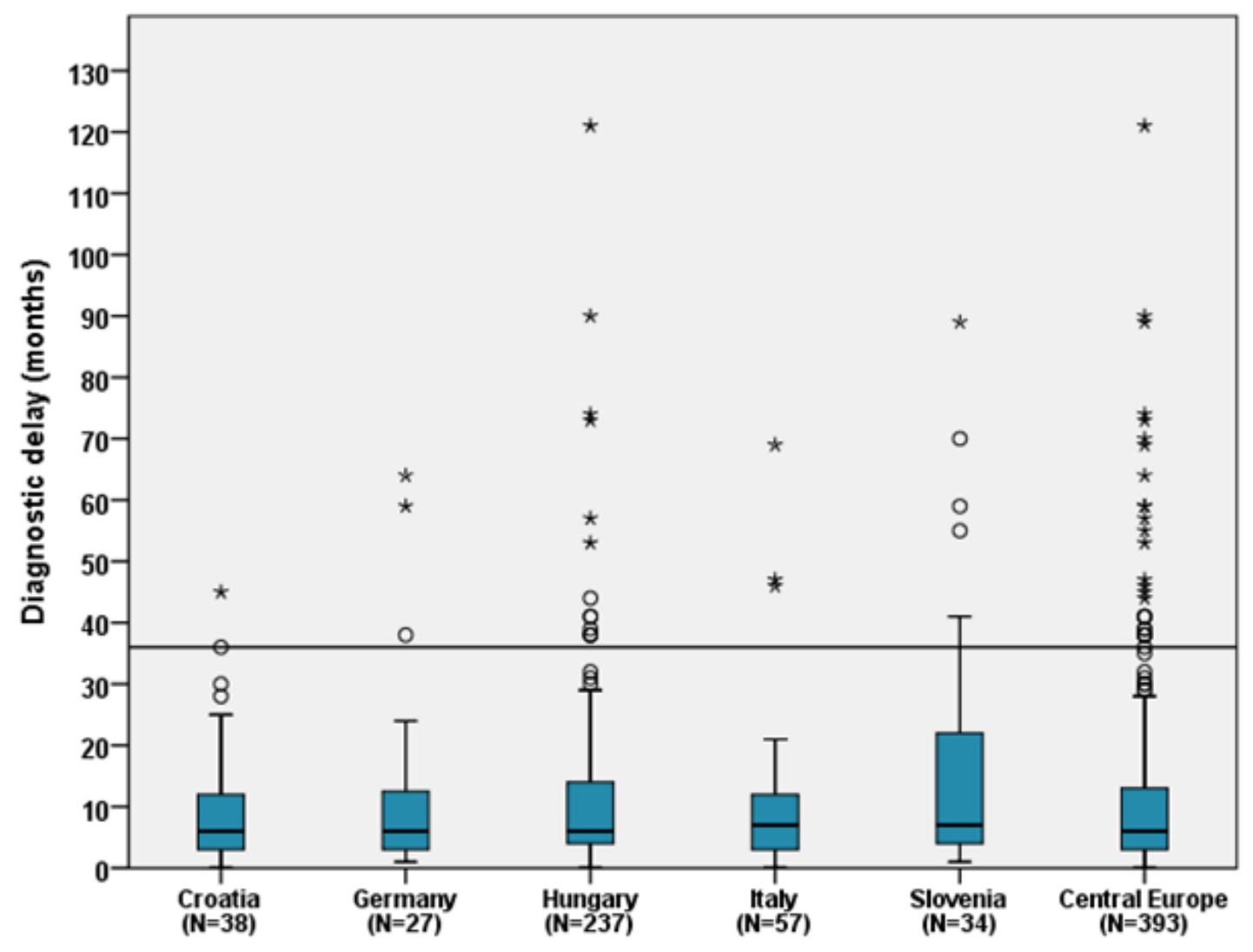


Table 1. Descriptive statistics and diagnostic delays in children with CD in Central European region in 2016.

\begin{tabular}{|c|c|c|c|c|c|c|}
\hline & Croatia & Germany & Hungary & Italy & Slovenia & TOTAL \\
\hline $\begin{array}{l}\text { Number of participating } \\
\text { centres }\end{array}$ & 6 & 5 & 21 & 2 & 7 & 41 \\
\hline $\begin{array}{l}\text { Number of patients } \\
\text { (preschool) }\end{array}$ & $38(13)$ & $27(14)$ & $\begin{array}{c}237 \\
(102) \\
\end{array}$ & $57(31)$ & $34(14)$ & $\begin{array}{c}393 \\
(174) \\
\end{array}$ \\
\hline $\begin{array}{l}\text { Age at diagnosis (years) } \\
\text { Median [range] }\end{array}$ & $\begin{array}{c}9[7 \mathrm{~m}- \\
18 \mathrm{y}]\end{array}$ & $\begin{array}{l}6[13 \mathrm{~m}- \\
18 \mathrm{y}]\end{array}$ & $\begin{array}{l}7[15 \mathrm{~m}- \\
18 \mathrm{y}]\end{array}$ & $\begin{array}{l}5[14 \mathrm{~m}- \\
16.5 \mathrm{y}]\end{array}$ & $\begin{array}{c}7.5 \\
{[14 \mathrm{~m}-} \\
18.5 \mathrm{y}]\end{array}$ & $\begin{array}{l}7[7 \mathrm{~m}- \\
18.5 \mathrm{y}]\end{array}$ \\
\hline \multicolumn{7}{|c|}{$\begin{array}{l}\text { Time from } 1^{\text {st }} \text { symptom until } 1^{\text {st }} \text { visit to PaedGI } \\
\text { Median (range) }\end{array}$} \\
\hline Overall & $\begin{array}{c}3 \mathrm{~m}(0- \\
3 y)\end{array}$ & $\begin{array}{c}4 \mathrm{~m}(0- \\
5.5 y)\end{array}$ & $\begin{array}{c}5 \mathrm{~m}(0- \\
10 y)\end{array}$ & $\begin{array}{c}6 \mathrm{~m}(0- \\
5.5 y)\end{array}$ & $\begin{array}{c}6 \mathrm{~m}(0- \\
7.5 y)\end{array}$ & $\begin{array}{l}5 \mathrm{~m}(0- \\
10 y)\end{array}$ \\
\hline Preschool & $\begin{array}{l}2 \mathrm{~m}(0- \\
1.5 \mathrm{y})\end{array}$ & $\begin{array}{c}6 \mathrm{~m}(0- \\
5.5 \mathrm{y})\end{array}$ & $\begin{array}{c}4 \mathrm{~m}(0- \\
3 \mathrm{y})\end{array}$ & $\begin{array}{c}5 \mathrm{~m}(0- \\
1.5 \mathrm{y})\end{array}$ & $\begin{array}{c}3 \mathrm{~m}(0- \\
1.5 \mathrm{y})\end{array}$ & $\begin{array}{l}4 \mathrm{~m}(0- \\
5.5 \mathrm{y})\end{array}$ \\
\hline School-aged* & $\begin{array}{l}3 \mathrm{~m}(0- \\
3 \mathrm{y})\end{array}$ & $\begin{array}{l}4 \mathrm{~m}(1 \mathrm{~m}- \\
5 \mathrm{y})\end{array}$ & $\begin{array}{c}5 \mathrm{~m}(0- \\
10 \mathrm{y})\end{array}$ & $\begin{array}{l}7 \mathrm{~m} \\
(2 \mathrm{~m}- \\
5.5 \mathrm{y})\end{array}$ & $\begin{array}{l}9 \mathrm{~m}(0- \\
7.5 \mathrm{y})\end{array}$ & $\begin{array}{c}5 \mathrm{~m}(0- \\
10 \mathrm{y})\end{array}$ \\
\hline \multicolumn{7}{|c|}{$\begin{array}{l}\text { Time from } \mathbf{1}^{\text {st }} \text { visit to PaedGI until diagnosis } \\
\text { Median (range) }\end{array}$} \\
\hline Overall** & $\begin{array}{c}2 \mathrm{~m}^{\# \#}(0- \\
3.5 \mathrm{y})\end{array}$ & $\begin{array}{l}0 \mathrm{~m}(0- \\
8 \mathrm{~m})\end{array}$ & $\begin{array}{c}1 \mathrm{~m}^{\#}(0- \\
1.5 \mathrm{y})\end{array}$ & $\begin{array}{l}1 \mathrm{~m}(0- \\
8 \mathrm{~m})\end{array}$ & $\begin{array}{c}1 \mathrm{~m}(0- \\
5 y)\end{array}$ & $\begin{array}{c}1 \mathrm{~m}(0- \\
5 y)\end{array}$ \\
\hline Preschool & $\begin{array}{c}1 \mathrm{~m}(0- \\
5 \mathrm{~m})\end{array}$ & $\begin{array}{c}0 \mathrm{~m}(0- \\
8 \mathrm{~m})\end{array}$ & $\operatorname{lm}(0-$ & $\begin{array}{l}1 \mathrm{~m}(0- \\
8 \mathrm{~m})\end{array}$ & $\begin{array}{c}1 \mathrm{~m}(0- \\
6 \mathrm{~m})\end{array}$ & $\begin{array}{l}1 \mathrm{~m}(0- \\
8 \mathrm{~m})\end{array}$ \\
\hline School-aged* & $\begin{array}{c}2 \mathrm{~m}^{\#}(0- \\
3.5 \mathrm{y})\end{array}$ & $\begin{array}{c}0 \mathrm{~m}(0- \\
3 \mathrm{~m})\end{array}$ & $\begin{array}{c}1 \mathrm{~m}^{\#}(0- \\
1.5 \mathrm{y})\end{array}$ & $\begin{array}{c}1 \mathrm{~m}(0- \\
4 \mathrm{~m})\end{array}$ & $\begin{array}{c}1 \mathrm{~m}(0- \\
5 \mathrm{y})\end{array}$ & $\begin{array}{c}1 \mathrm{~m}(0- \\
5 \mathrm{y})\end{array}$ \\
\hline \multicolumn{7}{|c|}{$\begin{array}{l}\text { Time from symptoms to diagnosis (diagnostic delay) } \\
\text { Median (range) }\end{array}$} \\
\hline Overall & $\begin{array}{c}6 \mathrm{~m} \mathrm{(0-} \\
4 \mathrm{y})\end{array}$ & $\begin{array}{c}6 \mathrm{~m}(1 \mathrm{~m}- \\
5.5 \mathrm{y})\end{array}$ & $\begin{array}{c}6 \mathrm{~m}(0- \\
10 y)\end{array}$ & $\begin{array}{c}7 \mathrm{~m}(0- \\
6 \mathrm{y})\end{array}$ & $\begin{array}{c}7 \mathrm{~m}(1- \\
7.5 \mathrm{y})\end{array}$ & $\begin{array}{c}\text { 6m }(0- \\
10 y)\end{array}$ \\
\hline Preschool & $\begin{array}{l}4 \mathrm{~m}(1 \mathrm{~m}- \\
1.5 \mathrm{y})\end{array}$ & $\begin{array}{l}7 \mathrm{~m}(1 \mathrm{~m}- \\
5.5 \mathrm{y})\end{array}$ & $\begin{array}{c}6 \mathrm{~m}(0- \\
3.5 \mathrm{y})\end{array}$ & $\begin{array}{l}6 \mathrm{~m}(0- \\
2 \mathrm{y})\end{array}$ & $\begin{array}{l}4 \mathrm{~m}(1 \mathrm{~m}- \\
2 \mathrm{y})\end{array}$ & $\begin{array}{c}5 \mathrm{~m}(0- \\
5.5 \mathrm{y})\end{array}$ \\
\hline School-aged* & $\begin{array}{l}8 \mathrm{~m}(0- \\
4 \mathrm{y})\end{array}$ & $\begin{array}{l}4 \mathrm{~m}(1 \mathrm{~m}- \\
5 \mathrm{y})\end{array}$ & $\begin{array}{l}7 \mathrm{~m}(1 \mathrm{~m}- \\
10 \mathrm{y})\end{array}$ & $\begin{array}{l}8 \mathrm{~m}(2 \mathrm{~m}- \\
6 \mathrm{y})\end{array}$ & $\begin{array}{l}17 \mathrm{~m}^{\#} \\
(1 \mathrm{~m}- \\
7.5 \mathrm{y})\end{array}$ & $\begin{array}{c}7 \mathrm{~m}(0- \\
10 \mathrm{y})\end{array}$ \\
\hline $\begin{array}{l}\text { Number of patients with } \\
\text { the diagnostic delay }>\mathbf{3 y}\end{array}$ & 1 & 3 & 13 & 3 & 6 & 26 \\
\hline
\end{tabular}

PaedGI - paediatric gastroenterologist; $\mathrm{m}$ - month; y - year; Kruskall Wallis $\mathrm{H}$ test and

Mann Whitney U test were used to compare groups;

$* \mathrm{p}<0.05 ; * * \mathrm{p}<0.001$

significance $(\mathrm{p}<0.05)$ vs Croatia

\# significance $(\mathrm{p}<0.05)$ vs Germany

\#\# significance $(p<0.05)$ vs Germany and vs Italy 
Table 2. Diagnostic delays and clinical presentation of CD.

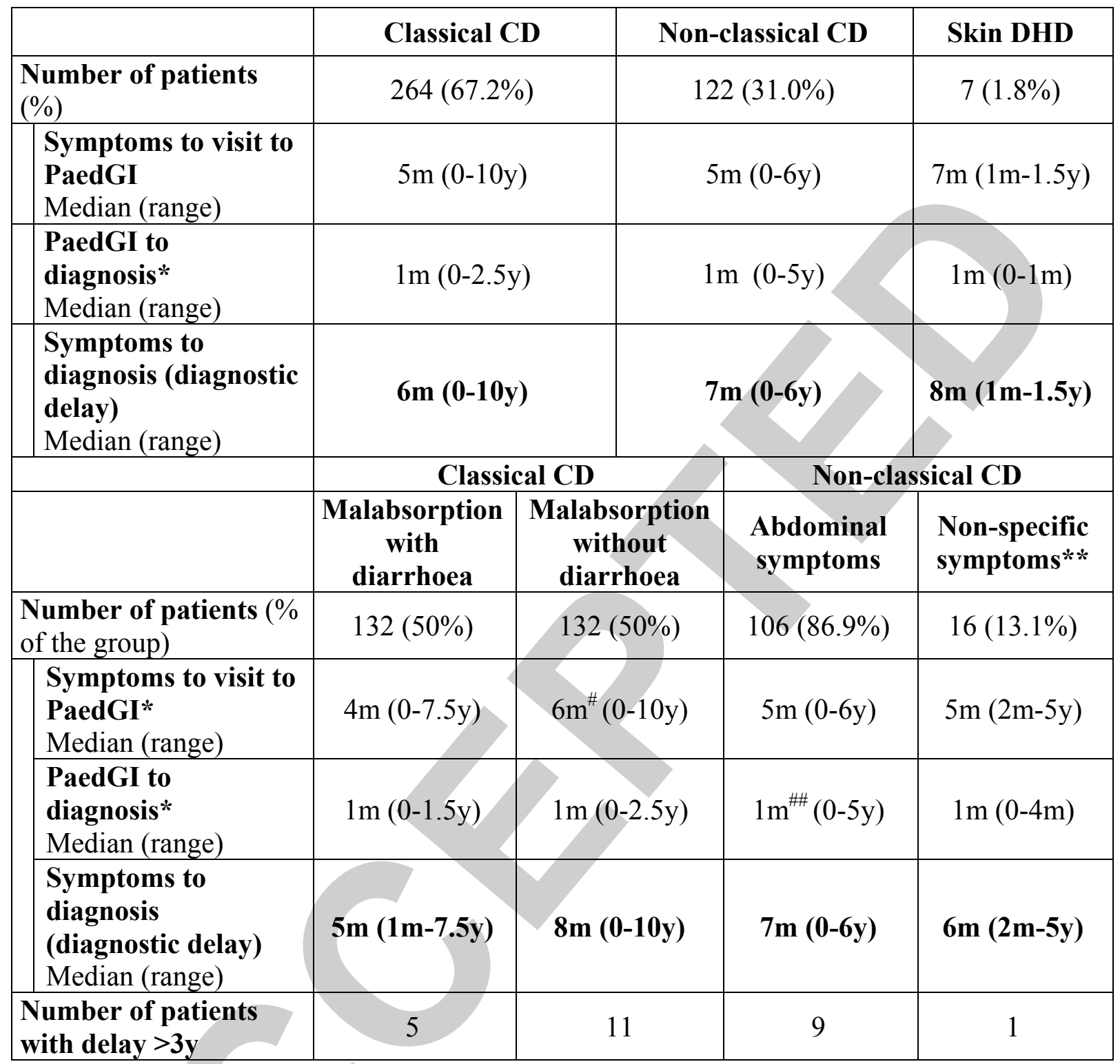

PaedGI - paediatric gastroenterologist; $\mathrm{m}$ - month; $\mathrm{y}$ - year; DHD - dermatitis herpetiformis Duhring

**non-specific symptoms: appetite loss, fatigue, irritability, headache, joint pain, skin rash (not DHD).

Kruskall Wallis H test and Mann Whitney U test were used to compare groups.

$* \mathrm{p}<0.05$

significance $(\mathrm{p}<0.05)$ vs Classical CD

\# significance $(\mathrm{p}<0.05)$ vs Malabsorption with diarrhoea

\#\# significance $(\mathrm{p}<0.05)$ vs Malabsorption without diarrhoea 